\title{
Distinguishing Quantitative Electroencephalogram Findings between Adjustment Disorder and Major Depressive Disorder
}

\author{
Hyun-Ghang Jeong ${ }^{1}$, Young-Hoon Ko ${ }^{2}$, Changsu Han², Yong-Ku Kim² and Sook-Haeng Joe ${ }^{1}$ \\ ${ }^{1}$ Department of Psychiatry, Korea University Guro Hospital, Korea University College of Medicine, Seoul, Republic of Korea \\ ${ }^{2}$ Department of Psychiatry, Korea University Ansan Hospital, Korea University College of Medicine, Ansan, Republic of Korea
}

Objective Adjustment disorder (ADJ) is a common diagnosis. However, it is difficult to distinguish ADJ from other major Axis I disorders, such as major depressive disorder (MDD). The aim of this study was to determine the distinguishing neurophysiological characteristics between $\mathrm{ADJ}$ and MDD using quantitative analysis of an electroencephalogram (QEEG).

Methods The study included 30 patients with ADJ and 51 patients with MDD. Resting (eye closed) vigilance controlled EEG recordings were assessed at 19 electrode sites according to the international 10/20 system. QEEG absolute power and coherence were calculated for the delta, theta, alpha and beta bandwidths.

Results Absolute powers of alpha and high beta bands, particularly at the frontocentral area, differed between MDD and ADJ group $(\mathrm{p}<0.05)$. Interhemispheric coherence values for the delta and beta bands were lower in the ADJ group than in the MDD group ( $<<0.05$ ). Intrahemispheric coherence values for the alpha band were also lower in the ADJ group $(\mathrm{p}<0.05)$.

Conclusion The differences in QEEG power and coherence in our investigation suggest that underlying pathophysiologic mechanisms may be different between $\mathrm{ADJ}$ and MDD.

Psychiatry Investig 2013;10:62-68

Key Words Adjustment disorder, Major depressive disorder, Electroencephalography, Computer-assisted signal processing, Power, Coherence.

\section{INTRODUCTION}

Adjustment disorder (ADJ) is a common diagnosis, particularly in primary care and general medical settings. ADJ has been diagnosed in up to $35 \%$ of patients who are referred to a mental health consultation, and in $5-20 \%$ of those in psychiatric health outpatient settings. ${ }^{1,2}$ Diagnosis of ADJ was more frequent than diagnosis of major depression in patients seen in a general hospital. ${ }^{3}$ However, there has been relatively little research done on this disorder.

While the concept of ADJ has evolved from Diagnostic and Statistical Manual for Mental Disorders (DSM)-I to DSM-IVtext revision (TR), criticism for the validity of the diagnosis of $\mathrm{ADJ}$ has always existed. ${ }^{4-6} \mathrm{ADJ}$, as a kind of subthreshold dis-

Received: May 11, 2012 Revised: July 18, 2012

Accepted: July 25, 2012 Available online: January 24, 2013

$\triangle$ Correspondence: Young-Hoon Ko, MD, PhD

Department of Psychiatry, Korea University Ansan Hospital, Korea University College of Medicine, 123 Jeokgeum-ro, Ansan 425-707, Republic of Korea

Tel: +82-31-412-5140, Fax: +82-31-412-5144, E-mail: korean@chol.com

(a) This is an Open Access article distributed under the terms of the Creative Commons Attribution Non-Commercial License (http://creativecommons.org/licenses/bync/3.0) which permits unrestricted non-commercial use, distribution, and reproduction in any medium, provided the original work is properly cited. order, is poorly defined and overlaps with other diagnostic categories. Both the DSM-IV ${ }^{1}$ and the International Classification of Diseases (ICD)-10 $10^{7}$ attempt to overcome this problem by specifying that if the criteria for another disorder are met, then the diagnosis of ADJ should not be made. However, it is difficult for clinicians to discriminate ADJ from other major Axis I disorders because depressive symptoms are most prominent in patients with ADJ. Content validity studies show that patients with $\mathrm{ADJ}$ are not distinguished from patients with major depression. ${ }^{8,9}$

There have been efforts to delineate features that are unique to $\mathrm{ADJ}$ as compared to major depression, suggesting descriptive validity. Patients diagnosed with ADJ have a lower severity of illness rating, a greater likelihood of improving in the hospital, a greater severity of stressors, better recent functioning and a greater likelihood of being rated as improved at follow-up. ${ }^{3,5,10}$ These studies have focused almost exclusively on the course of the disorder. Studies based on pathophysiologic differences that find ADJ to be a specific psychiatric disorder are rare in comparison with major depressive disorder (MDD).

The purpose of this study was to elucidate the distinguishing neurophysiologic findings between ADJ and MDD using 
the electroencephalogram (EEG). The quantitative analysis of EEG (QEEG) variables, with appropriate statistical methods, offer objective and reliable mechanisms for evaluating and extracting diagnostic and discriminating EEG variables. ${ }^{6,11}$ Despite several methodological limitations, QEEG variables have been used to investigate brain activity in psychiatric disorders. ${ }^{12,13}$ Relationships between psychiatric diagnostic categories and some QEEG variables have been examined in the attempt to characterize the QEEG abnormalities specific to a particular diagnosis. ${ }^{12,14}$ We hypothesized that there would be significant differences in QEEG absolute and relative power and coherence at the frontocentral area between patients with $\mathrm{ADJ}$ with depressed mood (ADJ group) and patients with MDD (MDD group) according to their different clinical characteristics. QEEG parameters at frontocentral area possibly reflect the circuitry dysfunction related to the fronto-limbic area known to be associated with mood regulation.

\section{METHODS}

\section{Subjects}

The subjects of this study were 30 patients with ADJ with depressed mood and 51 patients with MDD. All subjects were recruited from the outpatient department of Korea University Ansan Hospital. The patients were diagnosed through semistructured clinical interviews based on the DSM-IV by three neuropsychiatrist. They were all drug-naïve. The study protocol was approved by the Ethics Committee of Korea University Medical Center.

\section{EEG recording}

All EEG examinations were performed by the same technician. During the recording, the subjects lay in a semi-darkened, electrically shielded, sound-attenuated room with their eyes closed in a maximally alert state. The technicians monitored the EEG data during the recording and re-alerted the subjects every 30 seconds to avoid drowsiness. The EEG was recorded from Fp1, Fp2, F3, F4, C3, C4, P3, P4, O1, O2, F7, F8, T3, T4, T5, T6, Fz, Cz, and Pz sites according to the international 10/20 system with a linked mastoid reference.

\section{EEG data processing}

Artifact removal was performed off-line by an experienced physician using Neuroguide 2.3.5 software (Applied Neuroscience, Inc., St. Petersburg, FL, USA). EEG data were re-edited by visual inspection of any artifact that was undetected by the software's artifact rejection toolbox. We selected 30 artifact-free epochs of 2-second durations. The total duration of these epochs was 60 seconds. The time/amplitude series had a sampling frequency of $256 \mathrm{~Hz}$. Each digitized epoch of eye- closed EEG data was quantified using a fast Fourier transform ${ }^{15}$ algorithm to calculate absolute power $\left(\mu \mathrm{V}^{2}\right)$ and relative power (\%) in delta $(1-4 \mathrm{~Hz})$, theta $(4-8 \mathrm{~Hz})$, alpha $(8-12$ $\mathrm{Hz})$, beta $(12-25 \mathrm{~Hz})$ and high-beta $(25-30 \mathrm{~Hz})$ bands. Measures of interhemispheric coherence for each band were also computed for eight homologous sites (Fp1-Fp2, F7-F8, F3F4, C3-C4, P3-P4, O1-O2, T3-T4, T5-T6), and an additional set of sixteen electrode site pairs (Fp1-F3, F3-C3, C3-P3, P3O1, Fp1-F7, F7-T3, T3-T5, T5-O1, Fp2-F4, F4-C4, C4-P4, P4-O2, Fp2-F8, F8-T4, T4-T6, T6-O2) was used to derive measures of intrahemispheric coherence for each band.

\section{Statistical analysis}

The clinical and demographic characteristics of both groups were analyzed by independent $t$ test and $\chi$ squared test using SPSS 12.0 software (SPSS Inc., Chicago, IL, USA). Between groups, resting, eyes-closed measures of power and coherence were assessed by independent $t$-tests using the NeuroStat (Applied Neuroscience, Inc., St. Petersburg, FL, USA). All analyses were carried out separately for each of the frequency bands. Significance was set at $\mathrm{p}<0.05$.

\section{RESULTS}

\section{Sociodemographic data}

As shown in Table 1, the mean ages of the ADJ group and the MDD group were $38.4 \pm 11.8$ years and $37.33 \pm 10.41$ years, respectively. The mean age was not significantly different between the two groups ( $\mathrm{p}=0.683$ ). The percentage of male subjects $(n=17,56.7 \%)$ were greater in the ADJ group than in the MDD group ( $n=14,27.5 \% ; \mathrm{p}=0.017)$. In the ADJ group, health problems (53.3\%) were the most common type of predisposing stressor, followed by familial conflict (16.7\%), military problems (13.3\%), interpersonal problems (10\%) and occupational problems (6.7\%), in order. All subjects were right-handed.

\section{Absolute and relative power}

Comparing the mean absolute power value for every frequency band, there were significant differences in the alpha and high-beta bands between the ADJ and MDD groups, respectively, particularly in the right and left frontocentral areas (Table 2 and 3, Figure 1). The absolute alpha power was found to be lower in the ADJ group than in the MDD group at $\mathrm{Fp} 1(\mathrm{p}=$ 0.036), Fp2 ( $\mathrm{p}=0.031), \mathrm{F} 3(\mathrm{p}=0.025), \mathrm{F} 4(\mathrm{p}=0.022), \mathrm{F} 7(\mathrm{p}=$ $0.042), F 8(\mathrm{p}=0.023), \mathrm{C} 3(\mathrm{p}=0.039)$ and $\mathrm{C} 4(\mathrm{p}=0.034)$. The absolute high-beta power was also found to be lower in the ADJ group than in the MDD group, particularly at both the right and left frontocentral areas: at $\mathrm{Fp} 1(\mathrm{p}=0.035), \mathrm{Fp} 2(\mathrm{p}=0.022)$, $\mathrm{F} 3(\mathrm{p}=0.029), \mathrm{F} 4(\mathrm{p}=0.016), \mathrm{F} 7(\mathrm{p}=0.022), \mathrm{F} 8(\mathrm{p}=0.024), \mathrm{C} 3(\mathrm{p}=$ $0.019)$ and $\mathrm{C} 4(\mathrm{p}=0.028)$. In temporoparieatal areas, patients 
Table 1. Clinical characteristics of the study population

\begin{tabular}{lccc}
\hline & Patients with ADJ $(\mathrm{N}=30)$ & Patients with MDD (N=51) & p value \\
\hline Age & $38.4 \pm 11.8$ & $37.33 \pm 10.41$ & 0.683 \\
Male sex (\%) & 56.7 & 27.5 & 0.017 \\
Illness duration (days) & $43.73 \pm 20.15$ & & 0.008 \\
Type of stressor & & & \\
Health problem (\%) & 53.3 & \\
Familial conflict (\%) & 16.7 & \\
Military problem (\%) & 13.3 & \\
Interpersonal conflict (\%) & 10 & \\
Occupational problem (\%) & 6.7 & \\
\hline
\end{tabular}

ADJ: adjustment disorder, MDD: major depressive disorder

Table 2. Comparison of absolute power between ADJ and MDD group at frontocentral area

\begin{tabular}{|c|c|c|c|c|c|c|c|c|}
\hline & Fp1 & Fp2 & F3 & $\mathrm{F} 4$ & F7 & F8 & $\mathrm{C} 3$ & $\mathrm{C} 4$ \\
\hline \multicolumn{9}{|c|}{ Delta activity $\left(\mu \mathrm{V}^{2}\right)$} \\
\hline $\mathrm{ADJ}$ & $13.59(10.91)$ & $14.17(11.71)$ & $10.89(9.46)$ & $11.35(10.13)$ & $10.56(8.31)$ & $5.9(8.03)$ & $9.29(7.26)$ & $9.58(8.19)$ \\
\hline MDD & $21.14(29.72)$ & $23.46(33.8)$ & $12.89(13.48)$ & $13.73(14.69)$ & $14.49(17.55)$ & $19.76(26.02)$ & $10.68(11.58)$ & $11.06(11.96)$ \\
\hline $\mathrm{p}$ value & 0.106 & 0.078 & 0.436 & 0.392 & 0.177 & $0.033^{*}$ & 0.508 & 0.513 \\
\hline \multicolumn{9}{|c|}{ Theta activity $\left(\mu V^{2}\right)$} \\
\hline $\mathrm{ADJ}$ & $6.85(6)$ & $7.27(6.62)$ & $9.05(8.98)$ & $9.25(9.13)$ & $5.65(5.15)$ & $5.9(5.24)$ & $8.25(7.71)$ & $8.16(7.81)$ \\
\hline MDD & $9.62(15.11)$ & $10.29(16.4)$ & $11.68(19.14)$ & $12.46(20.79)$ & $7.52(10.93)$ & $8.24(11.97)$ & $9.61(13.18)$ & $9.58(12.91)$ \\
\hline $\mathrm{p}$ value & 0.249 & 0.248 & 0.406 & 0.342 & 0.302 & 0.230 & 0.562 & 0.539 \\
\hline \multicolumn{9}{|c|}{ Alpha activity $\left(\mu \mathrm{V}^{2}\right)$} \\
\hline $\mathrm{ADJ}$ & $11.08(9.16)$ & $11.45(9.69)$ & $14.26(11.65)$ & $14.69(11.74)$ & $8.55(7.04)$ & $8.57(6.77)$ & $14.77(12.22)$ & $14.53(11.77)$ \\
\hline MDD & $19.33(24.81)$ & $20.48(26.36)$ & $26.56(35.11)$ & $28.01(37.55)$ & $14.65(18.88)$ & $15.29(19.34)$ & $26.29(37.75)$ & $25.83(33.91)$ \\
\hline $\mathrm{p}$ value & $0.036^{*}$ & $0.031^{*}$ & $0.025^{*}$ & $0.022^{*}$ & $0.042^{*}$ & $0.023^{*}$ & $0.039^{*}$ & $0.034^{*}$ \\
\hline \multicolumn{9}{|c|}{ Beta activity $\left(\mu \mathrm{V}^{2}\right)$} \\
\hline ADJ & $5.89(4.43)$ & $5.89(4.58)$ & $7.46(6.16)$ & $7.44(6.07)$ & $4.82(3.78)$ & $4.92(3.95)$ & $7.98(6.84)$ & $7.73(6.41)$ \\
\hline MDD & $10.66(16.29)$ & $11.84(18.57)$ & $13.06(18.83)$ & $13.82(19.93)$ & $9.09(14.48)$ & $8.82(14.09)$ & $13.56(19.78)$ & $13.17(18.36)$ \\
\hline $\mathrm{p}$ value & 0.053 & 0.051 & 0.055 & $0.037^{*}$ & 0.051 & 0.068 & 0.071 & 0.058 \\
\hline \multicolumn{9}{|c|}{ High beta activity $\left(\mu V^{2}\right)$} \\
\hline ADJ & $1.28(1.17)$ & $1.1(0.78)$ & $0.82(1.02)$ & $1.17(0.92)$ & $1.16(0.65)$ & $0.84(0.56)$ & $1.01(0.8)$ & $0.98(0.79)$ \\
\hline MDD & $2.41(3.44)$ & $2.96(5.5)$ & $2.15(2.81)$ & $2.57(3.89)$ & $1.74(2.65)$ & $1.66(2.42)$ & $1.89(2.41)$ & $1.78(2.33)$ \\
\hline $\mathrm{p}$ value & $0.035^{*}$ & $0.022^{*}$ & $0.029^{*}$ & $0.016^{*}$ & $0.022^{*}$ & $0.024^{*}$ & $0.019^{*}$ & $0.028^{*}$ \\
\hline
\end{tabular}

Mean regional absolute power in $\mu \mathrm{V}^{2}$ (standard deviation). ${ }^{*}$ significant in independent t-test ( $\left.<<0.05\right)$. ADJ: adjustment disorder, MDD: major depressive disorder

with $\mathrm{ADJ}$ showed lower alpha power at T3 ( $\mathrm{p}=0.049)$, and lower high beta power at T5 ( $\mathrm{p}=0.021), \mathrm{P} 3(\mathrm{p}=0.028)$ and $\mathrm{P} 4 \mathrm{p}=$ 0.044 ) compared to patients with MDD. There were no significant differences in the delta, theta and beta activity between the two groups, except the absolute delta power at F8 (ADJ group $=5.9 \pm 8.03 ;$ MDD group $=19.76 \pm 26.02 ; \mathrm{p}=0.033)$ and the absolute beta power at F4 (ADJ group $=7.44 \pm 6.07$; MDD group $=13.82 \pm 19.93 ; \mathrm{p}=0.037$ ). There was no significant difference in the relative power between the two groups.

\section{Coherence}

The values for intrahemispheric coherence were higher in the MDD group than in the $\mathrm{ADJ}$ group for the 2 frequency bands in one pair of electrodes on the right side (Figure 2A and $\mathrm{C}$ ). The significant differences in intrahemispheric coherence value were pronounced between $\mathrm{P} 4 \mathrm{O} 2$ for the delta band (ADJ group=60.33 $\pm 13.08 ; \mathrm{MDD}$ group=66.85 $\pm 14.72 ; \mathrm{p}=$ 0.043 ) and the beta band (ADJ group $=53.83 \pm 14.61$; MDD group $=62.52 \pm 12.76 ; \mathrm{p}=0.009)$. Interhemispheric coherence values were higher in the MDD group than in the $\mathrm{ADJ}$ group 
Table 3. Comparison of absolute power between ADJ and MDD group at temporal and parietooccipital area

\begin{tabular}{|c|c|c|c|c|c|c|c|c|}
\hline & T3 & $\mathrm{T} 4$ & T5 & T6 & P3 & P4 & $\mathrm{O} 1$ & $\mathrm{O} 2$ \\
\hline \multicolumn{9}{|c|}{ Delta activity $\left(\mu \mathrm{V}^{2}\right)$} \\
\hline $\mathrm{ADJ}$ & $6.32(6.1)$ & $6.13(5.67)$ & $6.58(6.08)$ & $7.27(7.21)$ & $9.4(7.72)$ & $9.36(8.13)$ & $10.1(7.76)$ & $10.76(9.35)$ \\
\hline MDD & $7.24(9.13)$ & $7.43(7.73)$ & $6.08(9.07)$ & $7.21(10.65)$ & $10.85(12.64)$ & $11.2(13.51)$ & $11.48(17.84)$ & $12.92(20.48)$ \\
\hline $\mathrm{p}$ value & 0.587 & 0.389 & 0.638 & 0.695 & 0.525 & 0.446 & 0.633 & 0.519 \\
\hline \multicolumn{9}{|c|}{ Theta activity $\left(\mu \mathrm{V}^{2}\right)$} \\
\hline ADJ & $4.67(5.44)$ & $4.3(4.96)$ & $5.6(6.25)$ & $6(6.35)$ & $8.82(8.88)$ & $8.32(8.74)$ & $8.44(7.38)$ & $9.14(8.49)$ \\
\hline MDD & $4.83(5.93)$ & $4.89(6.16)$ & $5.83(7.44)$ & $5.89(7.86)$ & $9.15(11.54)$ & $9.11(11.41)$ & $9.42(13.35)$ & $10.08(13.8)$ \\
\hline $\mathrm{p}$ value & 0.9 & 0.642 & 0.884 & 0.943 & 0.885 & 0.727 & 0.672 & 0.706 \\
\hline \multicolumn{9}{|c|}{ Alpha activity $\left(\mu V^{2}\right)$} \\
\hline $\mathrm{ADJ}$ & $6.05(5.14)$ & $6.41(5.74)$ & $12.36(14.46)$ & $19.18(38.6)$ & $19.91(21.63)$ & $19.15(19.15)$ & $32.9(38.3)$ & $39.69(64.08)$ \\
\hline MDD & $10.34(13.75)$ & $9.67(11.28)$ & $18.25(28.52)$ & $19.17(26)$ & $31.64(49.48)$ & $31(40.95)$ & $47.19(99.95)$ & $48.48(74.04)$ \\
\hline $\mathrm{p}$ value & $0.049^{*}$ & 0.089 & 0.222 & 0.999 & 0.146 & 0.082 & 0.364 & 0.576 \\
\hline \multicolumn{9}{|c|}{ Beta activity $\left(\mu \mathrm{V}^{2}\right)$} \\
\hline ADJ & $4.87(4.99)$ & $4.47(4.13)$ & $6.48(7.13)$ & $6.48(6.38)$ & $9.51(10.76)$ & $8.22(7.05)$ & $12.8(24.9)$ & $12.78(22.99)$ \\
\hline MDD & $9.6(17.55)$ & $8.14(13.59)$ & $10.18(17.16)$ & $9.83(16.85)$ & $14.18(20.55)$ & $14.12(21.09)$ & $16.58(27.93)$ & $17.87(32.47)$ \\
\hline $\mathrm{p}$ value & 0.076 & 0.078 & 0.222 & 0.207 & 0.184 & 0.071 & 0.531 & 0.413 \\
\hline \multicolumn{9}{|c|}{ High beta activity $\left(\mu \mathrm{V}^{2}\right)$} \\
\hline ADJ & $0.8(1.11)$ & $0.68(0.63)$ & $0.62(0.55)$ & $0.67(0.59)$ & $0.87(0.72)$ & $0.85(0.71)$ & $0.93(0.98)$ & $0.89(0.92)$ \\
\hline MDD & $2.09(5.76)$ & $1.46(2.82)$ & $1.32(2)$ & $1.06(1.42)$ & $1.6(2.11)$ & $1.43(1.79)$ & $1.55(2.3)$ & $1.48(2.18)$ \\
\hline $\mathrm{p}$ value & 0.126 & 0.063 & $0.021^{*}$ & 0.063 & $0.028^{*}$ & $0.044^{*}$ & 0.096 & 0.098 \\
\hline
\end{tabular}

Mean regional absolute power in $\mu \mathrm{V}^{2}$ (standard deviation). *significant in independent $\mathrm{t}$-test $(\mathrm{p}<0.05)$. ADJ: adjustment disorder, MDD: major depressive disorder

that between F3F4 (ADJ group=76.48 \pm 15.44 ; MDD group= 83.28 $\pm 9.93 ; \mathrm{p}=0.036)$ and T3T4 (ADJ group $=14.98 \pm 15.11$; MDD group $=23.64 \pm 22.31 ; \mathrm{p}=0.041)$ for the alpha band (Figure $2 \mathrm{~B})$.

\section{DISCUSSION}

The present study evaluated the differences in the QEEG characteristics between patients with ADJ and patients with MDD by assessing QEEG power and coherence. The major findings in this study, which distinguished ADJ with depressed mood from MDD, were as follows. First, significant differences were found in the absolute alpha and high-beta powers of QEEG parameters between the ADJ and MDD group, particularly in the frontocentral area. Second, the intrahemishperic coherence values at the right posterior area and the interhemispheric coherence values at the frontal and temporal areas were significantly lower in the ADJ group than in the MDD group.

In this study, patients with ADJ showed significantly lower absolute alpha and high-beta powers compared to those with MDD. This difference in the power spectrum may be related to the different characteristics or pathophysiology of the two disorders. The QEEG power value is usually stable because of homeostatic regulation in healthy controls, ${ }^{16}$ and it is believed to sensitively detect brain dysfunction in patients with some psychiatric disorders with excesses or deficits of any of the neurotransmitters. ${ }^{17,18}$ Abnormal QEEG findings in patients with mood disorders have been reported in many previous studies, and the changes in the power amplitude were different in different disorders. For example, alpha activity was increased in unipolar depression, but decreased in bipolar disorder. ${ }^{19-22}$

Different alpha powers between the ADJ group and the MDD group may be associated with the different severity of depressive symptoms between the two disorders. Accumulated data have shown increased alpha power in a high percentage of depressed patients. ${ }^{21,23}$ As depressive symptoms are relieved by antidepressant, the alpha activity is reduced. ${ }^{24,25}$ It suggests that the alpha power could vary according to the severity of depressive symptoms. Depression is a common symptom in both $\mathrm{ADJ}$ and MDD. However, the depressive symptoms in adjustment disorder generally do not meet the threshold for criteria for major depression. ADJ is classified into subsyndromal depression together with dysthymia or minor depression. The difference in alpha power is probably due to the lesser depressive symptoms in the ADJ group than in the MDD group. However, we cannot exclude the possibility that the difference in alpha activity between the ADJ group and the MDD group is attributed to the comorbid anxiety symptom. 
Diminished alpha activity has been found in patients with anxiety disorder compared to healthy controls. ${ }^{26}$ Existing comorbid anxiety symptom in the patients with ADJ may contribute to their relatively lower alpha activity compared to that of depressed patients.

Another significant difference between the ADJ and MDD groups was found in the QEEG power spectrum for the highbeta band and beta band. Previously, EEG spectral analyses

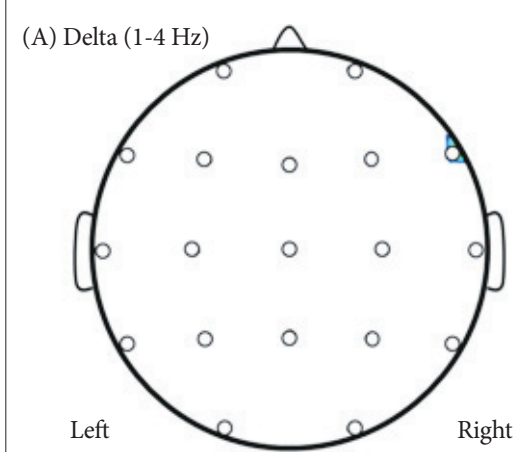

(B) Alpha $(8-12 \mathrm{~Hz})$

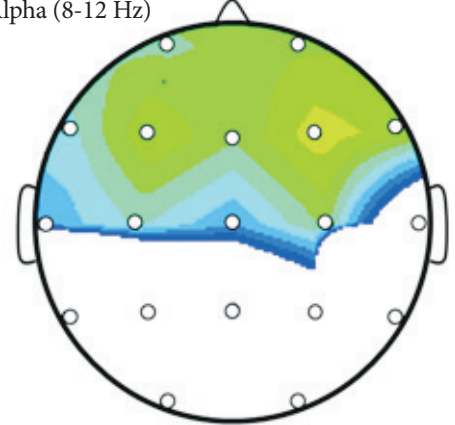

(C) Beta $(12-25 \mathrm{~Hz})$

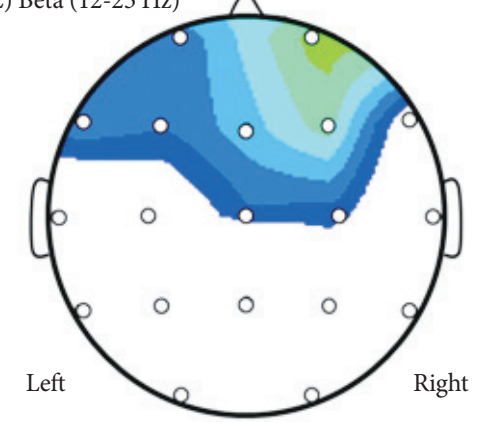

(D) High beta $(25-30 \mathrm{~Hz}) \wedge$

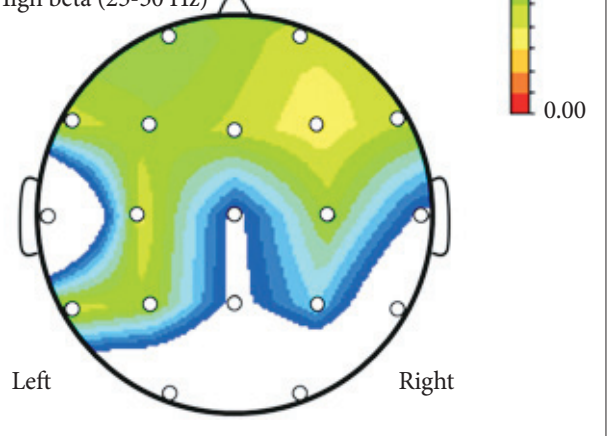

Figure 1. Probability maps of electroencephalogram absolute power of subjects with adjustment disorder compared to subjects with major depressive disorder. A colored area represents a decrease of absolute power.

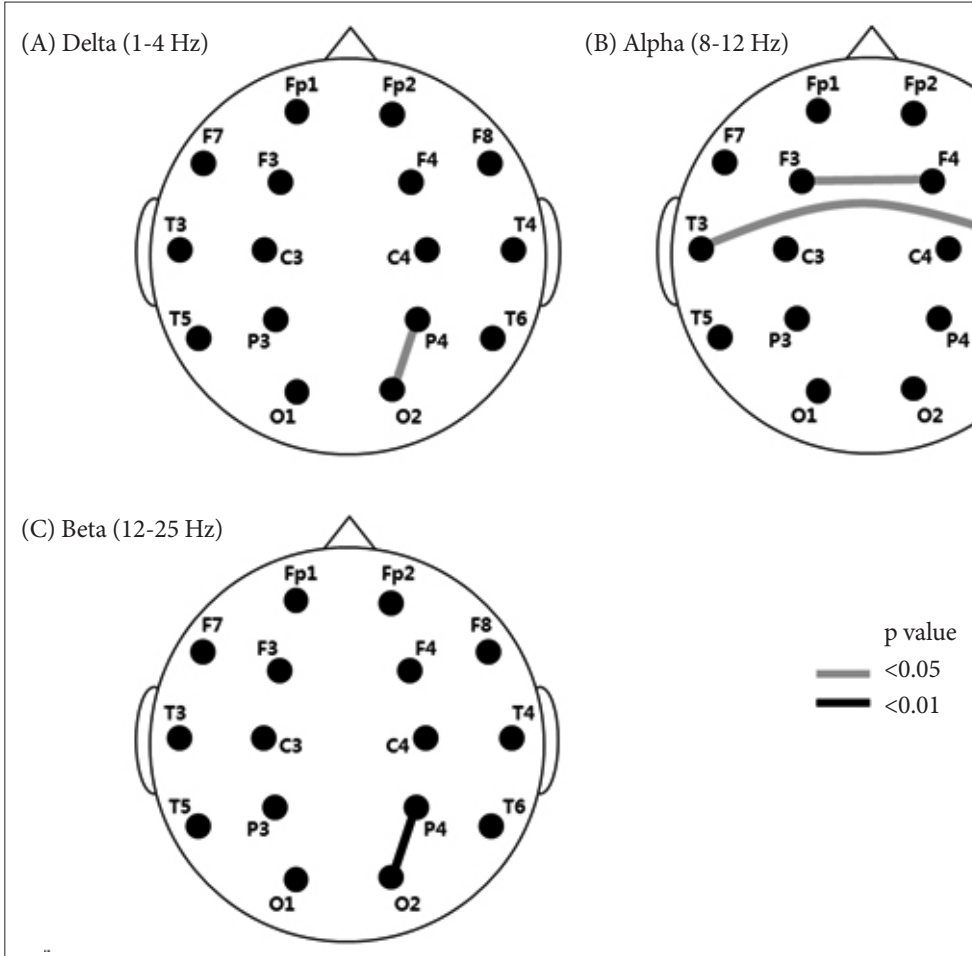

Figure 2. Interhemispheric and intrahemispheric coherence of subjects with adjustment disorder compared to subjects with major depressive disorder. A black and gray line connecting the two electrodes involved represents a decrease of coherence. 
and brain source localization revealed excessive high-beta activity of MDD patients in the frontal region. ${ }^{27}$ The excessive high-beta activity in frontocentral area is possibly interpreted as an exaggerated or maladaptive compensatory process resulting in psychomotor agitation and rumination, ${ }^{28}$ and the high-beta activity may be correlated with the frequency of ruminative processes. ${ }^{29}$ Our results suggest that the difference in high-beta power between the ADJ and MDD groups might be attributed to the different severity and characteristics of depressive symptoms. Matousek ${ }^{30}$ reported that heightened beta activity in unmedicated, actively depressed patients was positively correlated with a recurrent course of depression. Compared with MDD, spontaneous symptomatic relief is more common in ADJ. ${ }^{31}$ The different progression of each disorder may be related to the significantly different beta power between the ADJ and MDD groups in our study. Overall, the QEEG power spectrum in our results might reflect the different characteristics of ADJ and MDD.

Our second major finding is the significant difference in coherence values between the ADJ and MDD groups. EEG coherence is one way to quantify the cortical connectivity between two spatially distributed points of the brain..$^{32}$ Coherence studies can assess the loss of connections between neurons in the brain. There may be differences in either the density of the cortico-cortical connections or synaptic strengths of the connections between two brain areas or in subcortical input involving nerurotransmitters, such as serotonin, dopamine and acetylcholine. ${ }^{33,34}$ Previous studies have postulated the existence of subcortical circuits involved in mood regulation. ${ }^{35-37}$ Because these circuits are dependent upon positive and negative feedback pathways between brain structures, white matter lesions could make some patients more vulnerable to depression by damaging one or more limbs of these pathways. ${ }^{3}$ Measurement of QEEG coherence could detect the effect of lesions on the integrity of these pathways. Our results for QEEG coherence suggest pathophysiologic differences in circuitry function related to developing the affective symptoms of ADJ and MDD and may reflect different vulnerability to the mood symptoms of these two disorders.

Differences between the two groups in intrahemispheric coherence for both beta and delta bands at the parito-occiptial area were found in this study. Previous studies reported that EEG coherence for beta activity was significantly correlated with the emotional processing especially after negative emotive stimuli ${ }^{38}$ and that EEG delta and beta coherence was related to the response to threatening stimuli. ${ }^{39}$ Therefore, the significant difference in coherence values in our results might be associated with the different responses to stressors between patients with ADJ and MDD. In addition, the differences in interhemispheric coherence in the frontotemporal areas be- tween the two groups may result from the different susceptibility of the frontolimbic circuitry function to stress. ${ }^{40}$ These findings suggest that patients with $\mathrm{ADJ}$ may be more vulnerable to the negative stress in excess of what would be expected from exposure to a stressor ${ }^{1}$ although patients with MDD may show marked distress during the illness period. ${ }^{41-43}$

Our results provide an important electrophysiologic basis for the different characteristics of ADJ and MDD. However, there were some limitations in this study. One limitation of this study was that a normal control group was not incorporated. We identified differences between the two groups, but we could not identify the specific features of QEEG for ADJ and MDD. The results of this study should be interpreted with caution because the differences we identified did not indicate an abnormality of either the ADJ group or the MDD group. In spite of this limitation, this study suggests that QEEG might be useful to distinguish $\mathrm{ADJ}$ from MDD, supporting the validity of the diagnosis of the ADJ. Future research including a normal population is needed to uncover the temporal change in the characteristics of QEEG before and after treatment.

In conclusion, the differences in QEEG power and coherence in our investigation could provide important clues to the underlying pathophysiologic mechanisms that distinguish ADJ from MDD. These QEEG findings may be related to the vulnerability of brain circuitry functions to stressors, the severity of symptoms, and the progression of the disease. In the future QEEG can be considered a useful adjunct to clinical evaluation in the differential diagnosis of ADJ and MDD.

\section{Acknowledgments}

The authors appreciate the cooperation of the participants and staff in our department. The study was partly supported by YUNGJIN Pharmaceuticals. YUNGJIN had no further role in the study design; in the collection, analysis, or interpretation of data; in the writing of the manuscript; or in the decision to submit the paper for publication.

\section{REFERENCES}

1. American Psychiatric Association. Diagnostic and Statistical Manual of Mental Disorders, 4th Edition. Washington, DC: American Psychiatric Association; 1994.

2. Casey P. Adjustment disorder: epidemiology, diagnosis and treatment. CNS Drugs 2009;23:927-938.

3. Snyder S, Strain JJ, Wolf D. Differentiating major depression from adjustment disorder with depressed mood in the medical setting. Gen Hosp Psychiatry 1990;12:159-165.

4. Fard K, Hudgens RW, Welner A. Undiagnosed psychiatric illness in adolescents. A prospective study and seven-year follow-up. Arch Gen Psychiatry 1978;35:279-282.

5. Greenberg WM, Rosenfeld DN, Ortega EA. Adjustment disorder as an admission diagnosis. Am J Psychiatry 1995;152:459-461.

6. Semprini F, Fava GA, Sonino N. The spectrum of adjustment disorders: too broad to be clinically helpful. CNS Spectr 2010;15:382-388.

7. World Health Organization. International Classification of Disease and Related Health Problems, 10th Revision Edition. Geneva: World Health Organization; 1992. 
8. Aoki T, Hosaka T, Ishida A. Psychiatric evaluation of physical rehabilitation patients. Gen Hosp Psychiatry 1995;17:440-443.

9. Despland JN, Monod L, Ferrero F. Clinical relevance of adjustment disorder in DSM-III-4 and DSM-IV. Compr Psychiatry 1995;36:454-460.

10. Bronisch T. Adjustment reactions: a long-term prospective and retrospective follow-up of former patients in a crisis intervention ward. Acta Psychiatr Scand 1991;84:86-93.

11. Sulg I. Quantitative EEG as a measure of brain dysfunction. Prog Brain Res 1984;62:65-84.

12. Coburn KL, Lauterbach EC, Boutros NN, Black KJ, Arciniegas DB, Coffey CE. The value of quantitative electroencephalography in clinical psychiatry: a report by the Committee on Research of the American Neuropsychiatric Association. J Neuropsychiatry Clin Neurosci 2006; 18:460-500.

13. Nuwer MR. Quantitative EEG: I. Techniques and problems of frequency analysis and topographic mapping. J Clin Neurophysiol 1988;5:1-43.

14. Prichep LS, John ER. QEEG profiles of psychiatric disorders. Brain Topogr 1992;4:249-257.

15. Cooley JW, Tukey JW. An algorithm for the machine calculation of complex Fourier series. Math Comput 1965;19:297-301.

16. Hughes JR, John ER. Conventional and quantitative electroencephalography in psychiatry. J Neuropsychiatry Clin Neurosci 1999;11:190208.

17. McCormick DA. Neurotransmitter actions in the thalamus and cerebral cortex and their role in neuromodulation of thalamocortical activity. Prog Neurobiol 1992;39:337-388.

18. Steriade M, Gloor P, Llinás RR, Lopes de Silva FH, Mesulam MM. Report of IFCN Committee on Basic Mechanisms. Basic mechanisms of cerebral rhythmic activities. Electroencephalogr Clin Neurophysiol 1990; 76:481-508.

19. Knott VJ, Lapierre YD. Computerized EEG correlates of depression and antidepressant treatment. Prog Neuropsychopharmacol Biol Psychiatry 1987;11:213-221.

20. Clementz BA, Sponheim SR, Iacono WG, Beiser M. Resting EEG in first-episode schizophrenia patients, bipolar psychosis patients, and their first-degree relatives. Psychophysiology 1994;31:486-494.

21. Pollock VE, Schneider LS. Quantitative, waking EEG research on depression. Biol Psychiatry 1990;27:757-780.

22. John ER, Prichep LS, Fridman J, Easton P. Neurometrics: computer-assisted differential diagnosis of brain dysfunctions. Science 1988;239: 162-169.

23. Nieber D, Schlegel S. Relationships between psychomotor retardation and EEG power spectrum in major depression. Neuropsychobiology 1992;25:20-23.

24. Ulrich G, Renfordt E, Zeller G, Frick K. Interrelation between changes in the EEG and psychopathology under pharmacotherapy for endogenous depression. A contribution to the predictor question. Pharmacopsychiatry 1984;17:178-183.

25. Ulrich G, Haug HJ, Fähndrich E. Acute vs. chronic EEG effects in maprotiline- and in clomipramine-treated depressive inpatients and the prediction of therapeutic outcome. J Affect Disord 1994;32:213-217.

26. Buchsbaum MS, Hazlett E, Sicotte N, Stein M, Wu J, Zetin M. Topographic EEG changes with benzodiazepine administration in generalized anxiety disorder. Biol Psychiatry 1985;20:832-842.

27. Pizzagalli DA, Nitschke JB, Oakes TR, Hendrick AM, Horras KA, Larson CL, et al. Brain electrical tomography in depression: the importance of symptom severity, anxiety, and melancholic features. Biol Psychiatry 2002;52:73-85.

28. Mayberg HS. Modulating dysfunctional limbic-cortical circuits in depression: towards development of brain-based algorithms for diagnosis and optimised treatment. Br Med Bull 2003;65:193-207.

29. Paquette V, Beauregard M, Beaulieu-Prévost D. Effect of a psychoneurotherapy on brain electromagnetic tomography in individuals with major depressive disorder. Psychiatry Res 2009;174:231-239.

30. Matousek M. EEG patterns in various subgroups of endogenous depression. Int J Psychophysiol 1991;10:239-243.

31. Bronisch T, Hecht H. Validity of adjustment disorder, comparison with major depression. J Affect Disord 1989;17:229-236.

32. Jeong J. EEG dynamics in patients with Alzheimer's disease. Clin Neurophysiol 2004;115:1490-1505.

33. Nunez PL, Katznelson RD. Electric Fields of the Brain: The Neurophysics of EEG. New York: Oxford University Press; 1981.

34. Thatcher R. Cyclic Cortical Reorganization: Origin of Human Cognitive Development. In: Dawson G, Fisher KW, Editors. Human Behavior and the Developing Brain. New York: Guilford Press, 1994, p.232-266.

35. Drevets WC. Geriatric depression: brain imaging correlates and pharmacologic considerations. J Clin Psychiatry 1994;55(Suppl A):71-81.

36. Drevets WC, Raichle ME. Neuroanatomical circuits in depression: implications for treatment mechanisms. Psychopharmacol Bull 1992;28: 261-274.

37. Price JL, Drevets WC. Neurocircuitry of mood disorders. Neuropsychopharmacology 2010;35:192-216.

38. Wei L, Li Y, Tang Y, Wang J. Brain functional connectivity in depression during emotion processing. Sheng Wu Yi Xue Gong Cheng Xue Za Zhi 2010;27:961-967.

39. Putman P. Resting state EEG delta-beta coherence in relation to anxiety, behavioral inhibition, and selective attentional processing of threatening stimuli. Int J Psychophysiol 2011;80:63-68.

40. Phillips ML, Drevets WC, Rauch SL, Lane R. Neurobiology of emotion perception I: The neural basis of normal emotion perception. Biol Psychiatry 2003;54:504-514.

41. Kendler KS, Kessler RC, Walters EE, MacLean C, Neale MC, Heath AC, et al. Stressful life events, genetic liability, and onset of an episode of major depression in women. Am J Psychiatry 1995;152:833-842.

42. Bidzińska EJ. Stress factors in affective diseases. Br J Psychiatry 1984; 144:161-166.

43. Tao M, Li Y, Xie D, Wang Z, Qiu J, Wu W, et al. Examining the relationship between lifetime stressful life events and the onset of major depression in Chinese women. J Affect Disord 2011;135:95-99. 